\title{
Does Micro Health Insurance Solve the Problem of Providing Accessible Healthcare to the Poor? Evidence from Niramoy Project, Bangladesh
}

\author{
Md. Mizanur Rahman ${ }^{1}$, Sakufa Chowdhury ${ }^{2}$
}

1Graduate Student, Department of Business Administration, Shahjalal University of Science \& Technology, Sylhet, BANGLADESH

2Assistant Professor, Department of Business Administration, Shahjalal University of Science \& Technology, Sylhet, BANGLADESH

\begin{abstract}
Billion of people in the world are out of reach from the modern health care facilities and medicine. Micro health insurance is one of the methods of providing accessible health care facilities to the poor. Micro health insurance in Bangladesh provides basic health care at an affordable rate for the poor and the ultra-poor. The traditional insurance program consists of front cash at each stage of service delivery, but micro health insurance scheme with its partneragent model based distribution channel cover the adequate risk protection, inclusivity of access, affordability and program sustainability. The results of the analysis showed that micro health insurance program in Bangladesh has improved at the present time, but the increased access cannot reduce the essential health-related costs of marginal household.
\end{abstract}

Keywords: Micro Health Insurance, Delivery and Distribution Channel, Healthcare to Poor

JEL Classification Code: G22; J65

\section{INTRODUCTION}

The poor people always bear a disproportionate share of disease and ill health. World Bank researches indicate that both cause poverty and result from them (Narayan and Patesch, 2000). Illness is very frequent in Bangladesh, and it's the main cause of poverty and many low-incomes households cannot afford the expense of medical treatment. Disease and ill health create dangerous threats to the lives and livelihood of the poor people, and many of health related issues of the Millennium Development Goals remain unattainable. Micro Health Insurance is an effective way to mitigate the risks. It's operated like any other insurance and pooling the risk, but it's targeted to the poor and ultra-poor people who cannot afford the cost of convectional insurance. Micro health insurance is one such innovation, which pooling the risks as well providing accessible health care to the poor. The effectiveness of micro health insurance is to reduce the OOP payment, increase the health and medical service and so that improve the financial condition of the poor people. 
Bangladesh is in a serious state of discrepancy in the advancement of microinsurance activity, especially in health contexts. To pull the risk, provide accessible health care micro health insurance, holistic design has been made entitled 'Niramoy'. The holistic design of micro health insurance requires all relevant partners under a common platform so that each partner can hold some risk of the experiment. To provide the accessible service to the poor people Niramoy made an agreement with a private 600-bed Medical College Hospital in a rural place, which can provide a large scale of services, both in-and-outpatient mode including emergency, to the poor people of the area. Several pharmaceutical companies have been integrated into the holistic design of Niramoy, and they provide drug with affordable cost with a large volume. Benefit packages have been designed and it's priced all help the poor and provides accessible health care.

\section{LITERATURE REVIEW}

Micro health insurance targeted the low-income people while the conventional health insurance avoids them, and micro health insurance do this with simplicity, affordability and accessibility. Micro health insurance is known as a risk management tool for low-income people. It covers the health risk expenditure shocks, reduces out-of-pocket health expenses and protects the poorer population from catastrophic health events. The instantaneous reason for micro health insurance is to reduce financial vulnerability of the poor during ill health. A study in India reveals that, health insured persons reduces $10 \%$ of out-of-pocket health expenditure and decreases the rate of catastrophic health events (Joglekar 2008). Micro health insurance provides accessible, cost effective medical facilitates to the poorer people health care, which they don't get in ordinary condition. In Bangladesh, poor people, ethnic minorities, sex workers and working children receive health care facilities through micro health insurance (Werner 2009). And micro health insurance provides a distinct set of health care benefits and services. Benefits include disastrous events such as surgery or more routine events as well as outpatient services or maternal care. Microinsurance products such as life, health and livestock if properly designed would go a long way in preventing the risks of further poverty (Ahsan, 2009; Dror, 2007 and Morduch, 2006). In the context of Tanzania, sick individuals with micro health insurance were $15 \%$ more likely to receive treatment than individuals with no microhealth insurance (Leatherman 2011). In fact, support of micro health insurance by ILO was to develop health care access to informal workers and low-income people, who is excluded from conventional health insurances (Churchill 2007). To recover out the answer does micro health insurance solves the trouble of providing accessible health care to the poor or not, it is significant to define poor first. Low income, informal working people are not inevitably all poor. In micro health insurance, people do not differentiate between real poor and other poor who are low income, but have sufficient money to meet their basic needs. If micro health insurance solves the problem of providing accessible health care to the poor, we will find to our revelation that many of the poorer population are firstly didn't cover under Micro Health Insurance (Roth 2007, Werner 2009). While few people are covered, but studies show that they do not benefit equally compared to higher low-income people (Ranson 2005).

\section{OBJectives}

The purpose of the study is to investigate, the success of micro health insurance to solve the problem of providing accessible health care to the poor. The specific objectives of the study are:

1. To explore the idea about micro health insurance

2. To find out the existing methods of providing service to the poor

3. To find out the problems of providing accessible health care 
4. To find the peoples willingness to join in micro health insurance

5. To suggest policies as corrective measures.

\section{MetHodology}

The paper is mostly based on information from secondary sources (Green Delta Insurance Company Limited and Institute of Microfinance (InM) Database). Information over the past several years has been gathered to analyze the problem of providing accessible health care to the poor.

\section{ANALYSIS AND RESULT}

Table 1 reveals the important insurable shocks are health, death, crop, property and livestock. Health emergency is the single most common shock that respondents had to face. In fact, about $54 \%$ of all crises were related to death and health.

Table 1: Nature of Shocks Facing By the Households during The Last Two Years (\%)

\begin{tabular}{|l|c|c|c|}
\hline Indicator & Program Area & Control Area & Total \\
\hline Death & 6 & 5 & 5 \\
\hline Health & 53 & 45 & 49 \\
\hline Crop & 13 & 15 & 14 \\
\hline Property & 12 & 13 & 13 \\
\hline Livestock & 16 & 21 & 18 \\
\hline
\end{tabular}

(Source: Microinsurance, Poverty and Vulnerability Baseline Survey Brief)

Out of Pocket Payments: To design the benefit package Nirmoy Project use the OOP payment data from the baseline survey and secondary information by consulting with local hospitals to re-evaluate the need and disease probabilities. The OOP payment data are as follows:

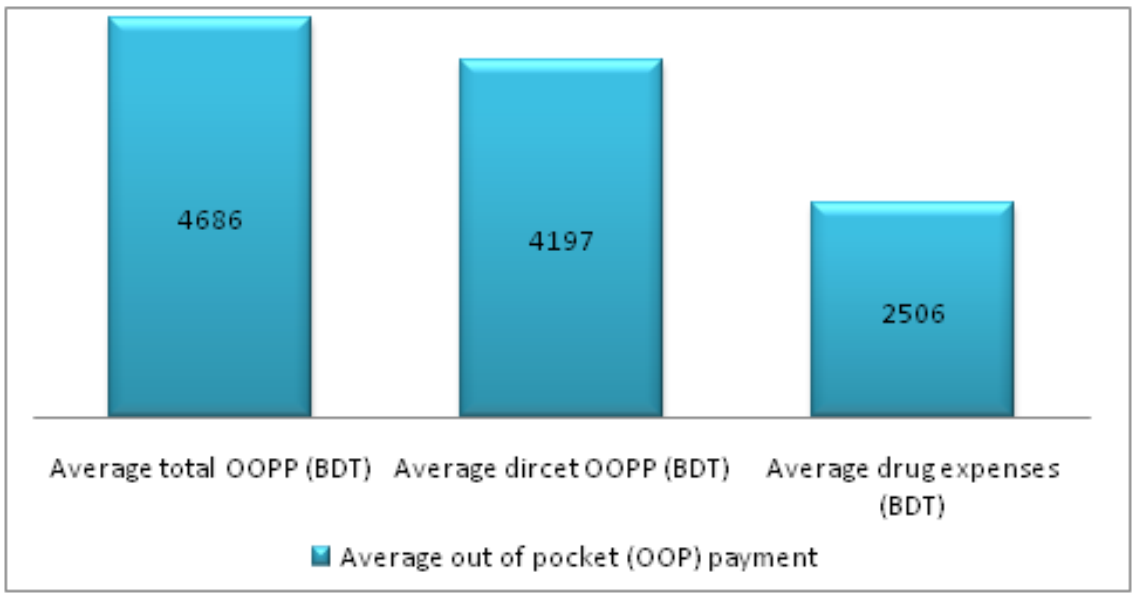

Figure 1 (a): Distribution of OOP Payments by Formal Provides per Episode (\%)

(Source: Microinsurance, Poverty and Vulnerability Baseline Survey Brief) 


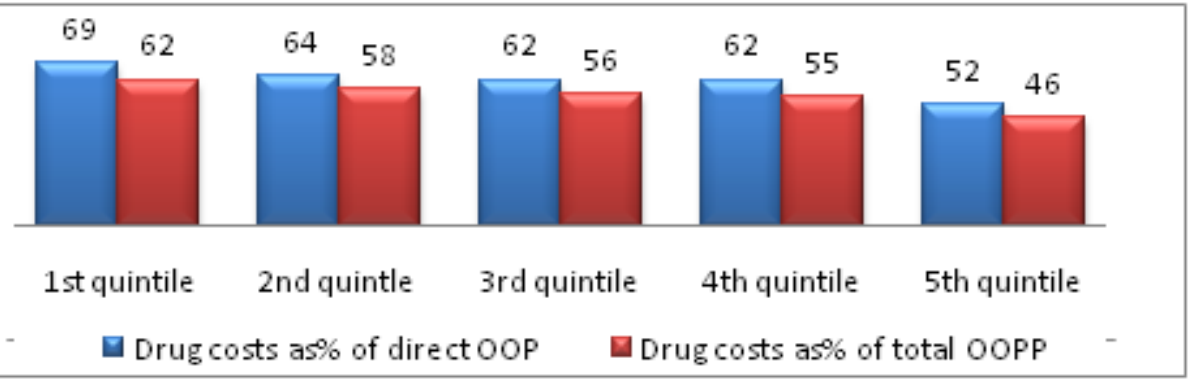

Figure 1 (b): Distribution of OOP Payments by Formal Provides per Episode (\%)

(Source: Microinsurance, Poverty and Vulnerability Baseline Survey Brief)

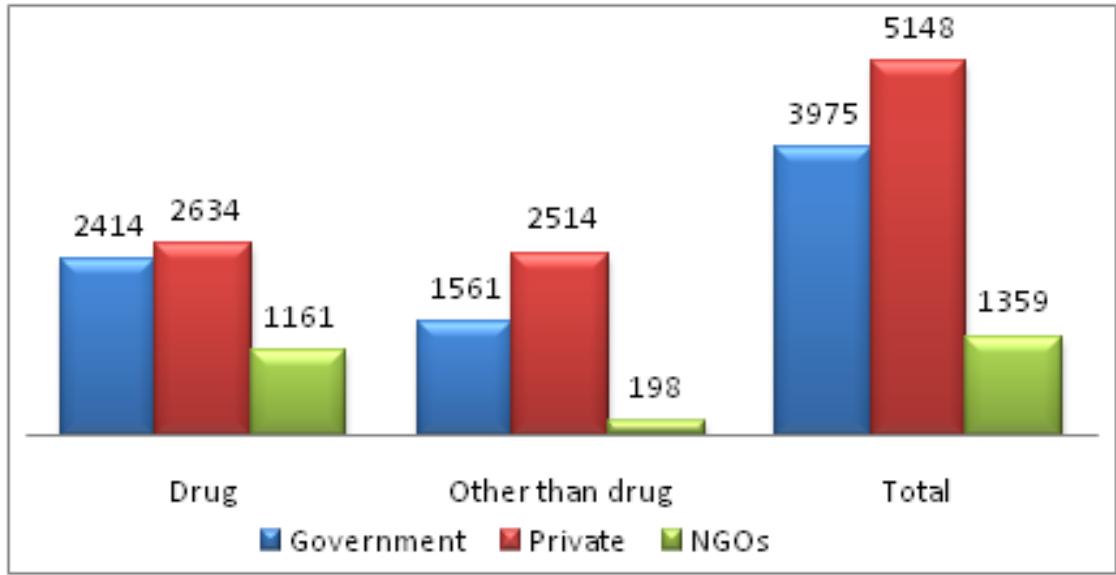

Figure 1 (c): Distribution of OOP Payments by Formal Provides per Episode (\%)

(Source: Microinsurance, Poverty and Vulnerability Baseline Survey Brief)

These above three graphs represent the OOP payment and this can be represented as follows:

- Total OOP payments per affected household during the 12 months preceding the survey stood at BDT 4,686. See Figure (all three panels)

- Direct OOP Payments per affected household during the 12 months preceding the survey was only a little lower at BDT 4,197.

- Annual OOP component for drug per affected household came to BDT 2,506, implying that drug costs constitute the largest element accounting for about $60 \%$ of direct and about $53 \%$ of total OOP costs.

- Total OOP payments come to about $6 \%$ of total household consumption.

Benefits, Co-Payments and Premium Structure: Over the twelve month period, a maximum of five outpatient visits have been set in a household of four and five members, three visits for a household of two or three members, six visits for a household of six or seven members, seven for a household of eight or nine members and eight visits for a household of more than nine members. 
Table 2: Benefits, Co-Payments and Premium Structure of Niramoy Scheme

\begin{tabular}{|c|c|c|c|c|c|}
\hline $\begin{array}{c}\text { No. of total insured } \\
\text { persons in the } \\
\text { household }(\mathrm{hh})\end{array}$ & $\begin{array}{c}\text { Eligible no. of } \\
\text { total outpatient } \\
\text { care visits per hh }\end{array}$ & $\begin{array}{c}\text { Eligible no. of } \\
\text { total inpatient } \\
\text { stays per hh }\end{array}$ & $\begin{array}{c}\text { Eligible no. of } \\
\text { maternity cases } \\
\text { per hh }\end{array}$ & $\begin{array}{c}\text { Co- } \\
\text { payment } \\
\text { on drugs } \\
\text { and } \\
\text { injectables }\end{array}$ & $\begin{array}{c}\text { Total } \\
\text { premium } \\
\text { per hh } \\
(380 \times \text { no. of } \\
\text { members) }\end{array}$ \\
\hline $\mathbf{2}$ & 3 & 2 & 1 & $20 \%$ & 760 \\
\hline 3 & 3 & 2 & 1 & $20 \%$ & 1140 \\
\hline 4 & 5 & 2 & 1 & $20 \%$ & 1520 \\
\hline $\mathbf{5}$ & 5 & 2 & 1 & $20 \%$ & 1900 \\
\hline $\mathbf{6}$ & 6 & 2 & 1 & $20 \%$ & 2280 \\
\hline $\mathbf{7}$ & 6 & 2 & 1 & $20 \%$ & 2660 \\
\hline $\mathbf{8}$ & 7 & 2 & 1 & $20 \%$ & 3040 \\
\hline $\mathbf{1 0}$ & 7 & 2 & 1 & $20 \%$ & 3820 \\
\hline
\end{tabular}

(Source: InM Working Paper 17)

Each eligible household in allowed to receive one complete maternal care including four Antenatal Checkups (ANC), delivery (normal or C-Section), two PNCs and neonatal care.

Table shows that, if we retain elementary illnesses like cold and fever than 70 per cent of households utilized no more than five visits to a provider. Actually a good share, indeed $18.6 \%$ of such visits were just to the corner drugstore, presumably without a prescription in most cases.

Table 3: Distribution of the Number of Visits

\begin{tabular}{|c|c|c|c|c|}
\hline \multirow[b]{2}{*}{$\begin{array}{l}\text { Number } \\
\text { of visits }\end{array}$} & \multicolumn{2}{|c|}{ All sampled districts $(\mathrm{N}=3,791)$} & \multicolumn{2}{|c|}{ Mymensingh ( $\mathrm{n}=743)$} \\
\hline & $\begin{array}{l}\text { Percentage of } \\
\text { hhs having the } \\
\text { corresponding } \\
\text { number of visits }\end{array}$ & $\begin{array}{l}\text { Cumulative } \\
\text { percentage of } \\
\text { hhs having the } \\
\text { corresponding } \\
\text { number of visits }\end{array}$ & $\begin{array}{l}\text { Percentage of } \\
\text { hhs having the } \\
\text { corresponding } \\
\text { number of visits }\end{array}$ & $\begin{array}{l}\text { Cumulative } \\
\text { percentage of } \\
\text { hhs having the } \\
\text { corresponding } \\
\text { number of visits }\end{array}$ \\
\hline 0 & 9.18 & 9.18 & 8.48 & 8.48 \\
\hline 1 & 11.42 & 20.60 & 10.90 & 19.38 \\
\hline 2 & 15.40 & 36.00 & 14.40 & 33.78 \\
\hline 3 & 12.85 & 48.85 & 14.00 & 47.78 \\
\hline 4 & 10.84 & 59.69 & 12.65 & 60.43 \\
\hline 5 & 9.15 & 68.84 & 8.48 & 68.91 \\
\hline 6 & 6.33 & 75.17 & 5.52 & 74.43 \\
\hline 7 & 5.41 & 80.58 & 5.79 & 80.22 \\
\hline 8 & 4.12 & 84.70 & 4.85 & 85.07 \\
\hline 9 & 3.30 & 88.00 & 4.58 & 89.65 \\
\hline 10 & 2.29 & 90.29 & 2.29 & 91.94 \\
\hline$>10$ & 9.71 & 100 & 8.08 & 100 \\
\hline
\end{tabular}

(Source: InM Working Paper 17

Impact of OOP Payments on Poverty: Table shows that, a major effect (over 3\%) of OOP payments on the poverty level of the households can be detected, while the incidence is much higher for inpatient or catastrophic health payments at about 11.6 and 17\%, respectively. 
Table 4: Illness \& Poverty

\begin{tabular}{|l|c|}
\hline \multicolumn{1}{|c|}{ Category of illnesses } & Poverty impact \% (Headcount) \\
\hline All episodes of illness & 3.40 \\
\hline Catastrophic events & 17.33 \\
\hline Acute illness & 2.66 \\
\hline Chronic illness & 4.65 \\
\hline Communicable diseases & 0.95 \\
\hline Non-communicable diseases & 4.61 \\
\hline In-patient cases & 11.58 \\
\hline Out-patient cases & 3.03 \\
\hline
\end{tabular}

(Source: Microinsurance, Poverty and Vulnerability Baseline Survey Brief)

Demand of Micro Health in Rural Bangladesh: The demand for micro health insurance in rural Bangladesh represents some fact, by using and developing the fact Niramoy delivery and distribution channels can be more effective and ensure accessible health care facilities to the poor. The graphs represent the demand for micro health insurance in rural Bangladesh, and the findings are given below the graphs.

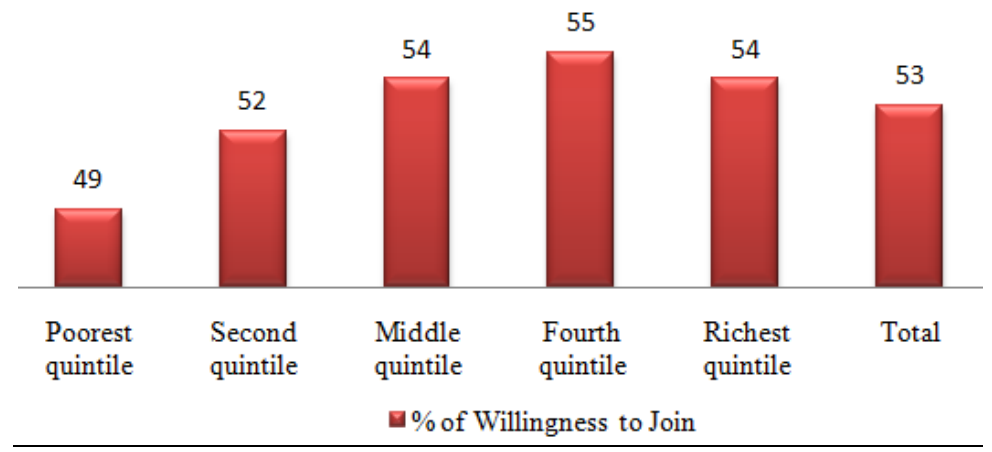

Figure: Willingness to Join (WTJ) by Consumption Quintiles (\%)

(Source: Microinsurance, Poverty and Vulnerability Baseline Survey Brief)

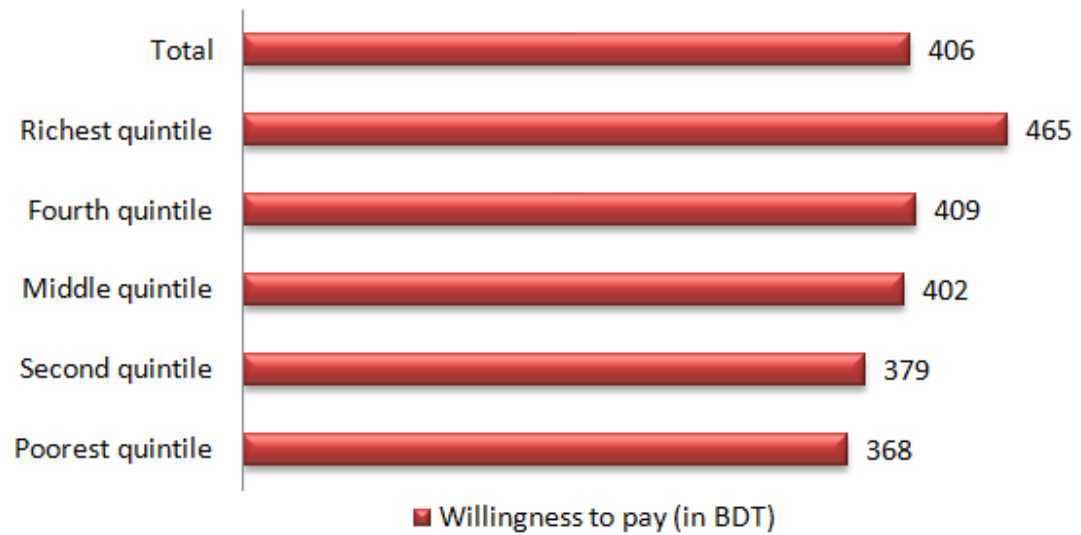

Figure 14: Willingness to Pay (WTP) by Consumption Quintiles (BDT)

(Source: Microinsurance, Poverty and Vulnerability Baseline Survey Brief) 
The results show that overall willingness to join (WTJ) was $54 \%$ and, among the latter group, the average household willingness to pay (WTP) was BDT 406 \pm 171 , which was well below the expected cost of providing the services in question.

Niramoy Project-Delivery Channel: Niramoy adoption the partner-agent model for providing accessible health care facilities with its unique delivery channels. The advantage of the partner-agent model is one or more NGOs/SHGs to 'sell' insurance as agents, where the service providers may be NGOs themselves or designated health facilities chosen by them. Another major advantage of the partner-agent setup is that the service providers may concentrate on their respective duties without having to worry about risk management themselves.

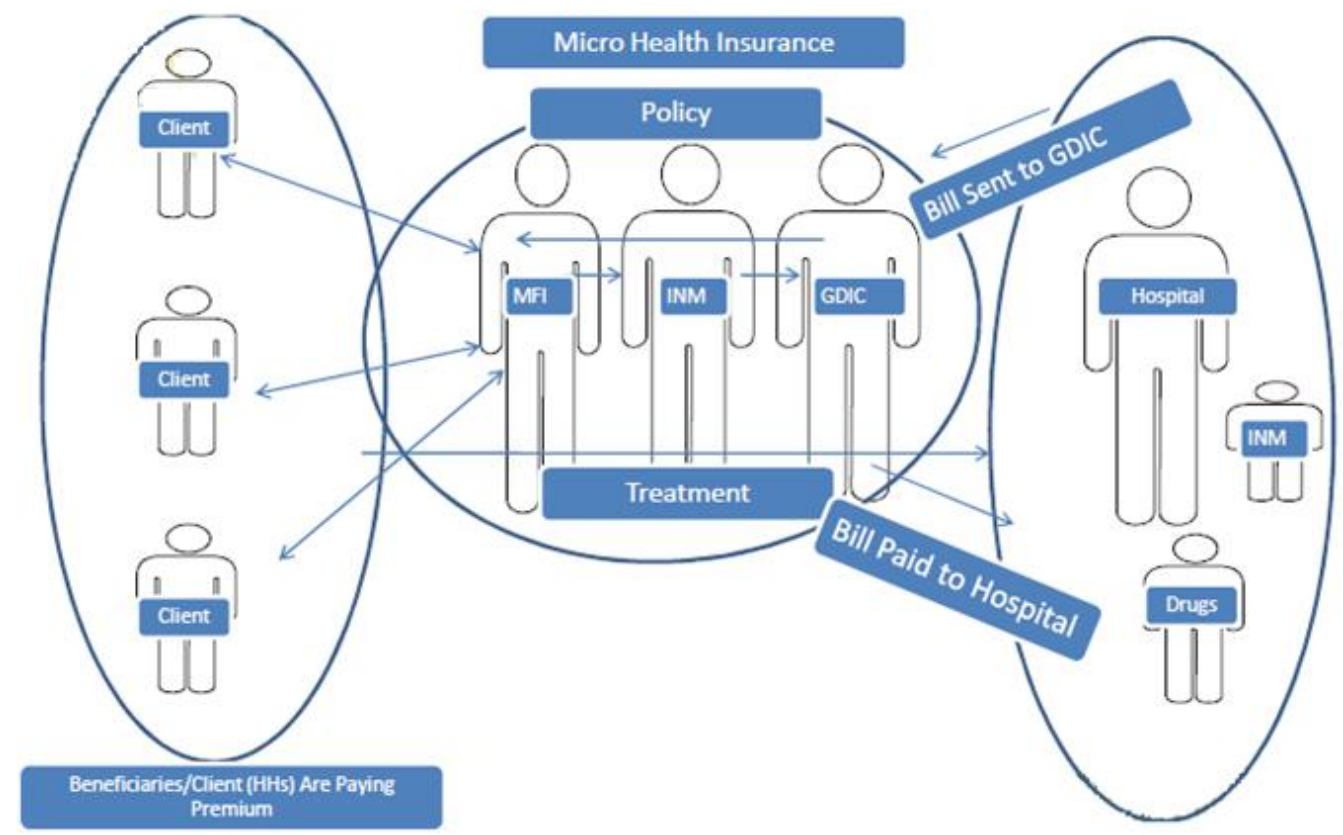

Figure 2: Niramoy Delivery Channel: Partner-Agent Model

(Source: Green Delta Insurance Company Limited)

In this model, the clients / beneficiaries (HHs) are paying the premiums to MFIs (ASPADA, POP and SSS) and the MFIs pays to InM. InM pays the premium to Green Delta Insurance Company Limited and they took the health risk and provide cash to $\mathrm{CBMCH}$ for treatment. The policy of MHI has implemented by the MFIs, InM and Green Delta Insurance Company Limited with other agents.

Exclusion Criteria: Niramoy has some exclusion criteria in their delivery and distribution channels. The exclusion criteria are:

a. Mother aged below 19 years will not be eligible for this benefit.

b. Mother with two living children will not be eligible for the service.

c. Mother who has had a living child of 12 months old or younger will not be eligible for the service.

Services of Niramoy Scheme: Niramoy provides services to poor in various modes like outpatient mode, In-patient mode and Maternity and Newborn care services. The details are given in below. 
Table 5: Diseases to Be Treated In the Outpatient Mode

\begin{tabular}{|c|c|c|c|c|}
\hline Angular & Stomatitis & Weakness & Urinary Tract & Infection \\
Chicken Pox & Gonorrhoea & Dengue & Diptheria & Tetanus \\
Diarrhea & Dysentery & Cholera & Typhoid & Malaria \\
Disease & Indigestion & Diabetes & Asthma & Breathing \\
Fever & Influenza & Cough-Cold & Arthritis & Abdominal Pain \\
Headache & Migraine & Back Pain & Acidity & Peptic Ulcer \\
Measles Problem & Mumps & Polio & Worm & Jaundice \\
Syphilis & Pneumonia & Anaemia & H/L BP & Sore Throat \\
Skin Diseases & Conjunctivitis & Otitis Media & Sinusitis & \\
\hline
\end{tabular}

Table 6: Maternity and Newborn Care Services

\begin{tabular}{|l|}
\hline 4 Antenatal Checkups (ANC) \\
\hline Diagnostic tests (including Ultrasonography) \\
\hline Normal Delivery / Caesarean section (as medically necessary) \\
\hline 2 Postnatal Checkups (PNC) \\
\hline Newborn care within 4 weeks (28 days) of delivery \\
\hline
\end{tabular}

Table 7: Treatments Performed at In-patient Mode

\begin{tabular}{|l|l|l|l|}
\hline \multicolumn{5}{|c|}{ Surgical Procedures } \\
\hline Appendectomy & Cholecystectomy & GI Perforation Repair & Hernia \\
\hline Caesarean Section & Orthopaedic Operation & Abscess Drainage & Piles \\
\hline Cataract Operation & Tonsillectomy & Renal Stone Removal & Fibroma \\
\hline \multicolumn{4}{|c|}{ Non-Surgical Procedures } \\
\hline Diarrhoea & Dysentery & Cholera & Typhoid \\
\hline Malaria & Chicken Pox & Dengue & Tetanus \\
\hline Measles & Pertussis & Jaundice & UTI \\
\hline Asthma & Polio & Breathing Problem & Pneumonia \\
\hline
\end{tabular}

\section{RECOMMENDATION}

The collected data, as well as the glaring omissions, suggest that micro health insurance service to the poor can become more effective and more sustainable over time. We try to summarize each of these elements in turn and then suggest some recommendation for the field of micro health insurance to solve the problem of providing accessible health care to the poor.

- In micro health insurance, member benefits should extend beyond hospitalization. Children health shocks are the major concern of the poor individuals and this demand need to resolve soon.

- Micro health insurance needs continuous improvement of product and process as well as ensuring the supply to the poor.

- Adequate health care services and personnel are within proximity to the patient is essential for the successful implication of micro health insurance.

- Metrics evaluation program need to implement to improve the evaluations of micro health insurance's success to providing accessible health care facilities to the poor.

- Without a large amount of the insured population, it would be very hard to pool risks and provide health care facilities. So, need to increase the amount of the insured population. 


\section{CONCLUSION}

With the comparison of other insurance policy, health insurance is still a latent sector in the formal insurance sector in Bangladesh. The present scheme of Niramoy attempts to involve commercial organization in the formal health insurance sector with ensuring the accessible health care service to the poor and that is the first attempts in Bangladesh. Niramoy project partner-agent model provide a new dimension in the innovation of micro health insurance with its unique delivery and distribution of health care facilities to the poor. Niramoy solves the problem of providing accessible health care to the poor by developing the method of the partner-agent model. The Niramoy partner agent model includes microfinance institutions, the commercial organization, prominent medicine manufacturer and medical service provider. The active involvement of a third party organization adds a new dimension to provide accessible health care to the poor.

Providing health care facilities to the poor is the key of micro health insurance and without the proper service form the health facilities provider the project will be a failure. And in Bangladesh that is very tough to provide health care service to all people. Some of the area doesn't have any medical for the people, and most of the area doesn't have adequate medical facilities to serve the people. Niramoy project considers the all of things and work with a unique model so that the poor people can receive accessible health care facilities.

\section{Reference}

Ahsan S. M., Hamid S. A. Barua S. (2013), Demand for Micro Health Insurance in Rural Bangladesh, Institute of Microfinance.

Ahsan S. M., Hamid S. A. Barua, S. (2010) Health Risks in Bangladesh: Can Microinsurance Prevent Vulnerability to Poverty?, Institute of Microfinance, InM Working Paper No. 03.

Ahsan S. M., Hamid S. A. Barua, S. (2012) Utilisation of Formal Health Care and Out-of-Pocket Payments in Rural Bangladesh, Institute of Microfinance, InM Working Paper No. 13.

Ahsan S. M., Hamid S. A. Barua, S. L. Tax Jaimie (2010), Toward an Efficient and Sustainable Microinsurance Market: The Regulatory Perspective, Institute of Microfinance, InM Working Paper No. 02.

Churchill, C. (2006), Protecting the Poor A Microinsurance Compendium, Munich Re Foundation, 80791 München, Germany.

Churchill, C. (2007). Insuring the Low-Income Market: Challenges and Solutions for Commercial Insurers, Palgrave Macmillan Journals, Volume: 32 (Issue: 3), pp 401-412.

Dodd R. Munck Lise (2002), Dying for Change Poor People's Experience of Health and Ill-health, World Health Organization, The World Bank, Voices of the Poor.

Dror, I. (2007), Demystifying Micro Health Insurance Package Design- Choosing Health Plans All Together (CHAT), Social Science Research Network, Microfinance Insights 4, 17-19.

Joglekar, R. Pal, R. (2008), Can Insurance Reduce Catastrophic Out-of-Pocket Health Expenditure? Indira Gandhi Institute of Development Research, IGIDR working paper, Mumbai, WP-2008-016.

Leatherman, S. Christensen L. J. and Holtz, J. (2010), Innovations and Barriers in Health Microinsurance: Micro Insurance Paper 6, Micro Insurance Innovation Facility, International Labour Organization, Geneva.

Morduch J. (2006) Micro-insurance: The Next Revolution?, Oxford University Press. National Medical Journal of India, Volume: 16 (Issue: 2) pp: 79-89.

Ranson M.K. Sinha T. Chatterjee M. Acharya A. Bhavsar A. Morris SS. Mills AJ. (2006), Making health insurance work for the poor: learning from the Self-Employed Women's Association's (SEWA) community-based health insurance scheme in India, Elsevier, Volume 62 (Issue:3) pp:707-720.

Ranson, M. K. (2003), Community-Based Health Insurance Schemes in India: A review, The 
Roth J. McCord M.J. Liber Dominic (2007), The Landscape of Micro Insurance in the World's 100 Poorest Countries, The MicoInsurance Center, LLC.

Werner, W. J. (2009), Micro-insurance in Bangladesh: Risk Protection for the Poor, International Centre for Diarrhoeal Disease Research, Bangladesh, Journal of Health Population and Nutrition, Volume: 27 (Issue: 4) pp:563-573

$$
--0--
$$

